\title{
Optimization Design of Spray Cooling Fan Based on CFD Simulation and Field Experiment for Horticultural Crops
}

\author{
Yongguang $\mathrm{Hu}{ }^{1,2, *}$, Yongkang Chen ${ }^{2} \mathbb{D}$, Wuzhe Wei ${ }^{2}$, Zhiyuan $\mathrm{Hu}^{2}$ and Pingping $\mathrm{Li}^{3}$ \\ 1 Key Laboratory of Modern Agricultural Equipment and Technology, Ministry of Education and Jiangsu \\ Province, School of Agricultural Engineering, Jiangsu University, Zhenjiang 212013, China \\ 2 Institute of Field Management Equipment, School of Agricultural Engineering, Jiangsu University, \\ Zhenjiang 212013, China; 2211816042@stmail.ujs.edu.cn (Y.C.); 2221816035@stmail.ujs.edu.cn (W.W.); \\ 2221816016@stmail.ujs.edu.cn (Z.H.) \\ 3 College of Biology and the Environment, Nanjing Forestry University, Nanjing 210037, China; \\ lipingping@ujs.edu.cn \\ * Correspondence: deerhu@ujs.edu.cn; Tel.: +86-138-1515-1176
}

\section{check for}

updates

Citation: $\mathrm{Hu}, \mathrm{Y}$.; Chen, Y.; Wei, W.; $\mathrm{Hu}, \mathrm{Z}$; Li, P. Optimization Design of Spray Cooling Fan Based on CFD Simulation and Field Experiment for Horticultural Crops. Agriculture 2021, 11, 566. https://doi.org/10.3390/ agriculture11060566

Received: 9 May 2021

Accepted: 31 May 2021

Published: 20 June 2021

Publisher's Note: MDPI stays neutral with regard to jurisdictional claims in published maps and institutional affiliations.

Copyright: (c) 2021 by the authors. Licensee MDPI, Basel, Switzerland. This article is an open access article distributed under the terms and conditions of the Creative Commons Attribution (CC BY) license (https:// creativecommons.org/licenses/by/ $4.0 /)$.

\begin{abstract}
In recent years, horticultural plants have frequently suffered significant heat damage due to excessive temperatures. In this study, a horticultural spray cooling system was designed, consisting mainly of a jet fan and spraying system. CFD simulation technology and response surface methodology were used to optimize the design of the jet fan, which improved the thrust of the fan. The length of the inlet section was $300 \mathrm{~mm}$, the length of the outlet section was $300 \mathrm{~mm}$, the length of the cone section was $450 \mathrm{~mm}$, and the diameter of the outlet was $950 \mathrm{~mm}$, where the thrust of the jet fan was $225.06 \mathrm{~N}$. By establishing the CFD model of spray cooling in a tea field and designing a $L_{9}\left(3^{4}\right)$ orthogonal experiment, the effect of the spray parameters on the maximum temperature drop and effective cooling distance was studied, and the best parameters were selected. The simulation results show that the optimum parameters are a spray flow rate of $4.5 \mathrm{~kg} / \mathrm{s}$, a droplet diameter of $15-45 \mu \mathrm{m}$, a droplet temperature of $298.15 \mathrm{~K}$, and a nozzle double circle layout. Based on the simulation results of the optimized jet fan and spray parameters selected, a spray cooling test bench was established. Field test results show that when the initial ambient temperature was $310.05 \mathrm{~K}-310.95 \mathrm{~K}$, the maximum temperature drop of the spray cooling fan was $9.1 \mathrm{~K}$, and the cooling distance was approximately $36.0 \mathrm{~m}$. The temperature drop decreased with increasing distance from the fan. This study is of great significance to protect horticultural plants from extremely high temperatures.
\end{abstract}

Keywords: spray cooling; CFD technology; jet fan; cooling effect

\section{Introduction}

In the context of global warming, extremely high-temperature climates occur frequently. Golf lawns, tea trees, fruit trees, and other plants with poor heat resistance are seriously affected by high-temperature heat damage, resulting in serious economic losses [1,2]. Through patent searches and literature reviews, the authors have conducted a large number of investigations and analyses of cooling technology in the field of horticulture at home and abroad and found that the main cooling measures are traditional shading, natural ventilation, mechanical ventilation, and spray evaporation and cooling [3-8]. However, for extremely high-temperature climates, the effect of natural ventilation and shading is limited and not sufficient to protect the normal growth of plants [9]. Mechanical ventilation and spray evaporative cooling are relatively effective cooling methods, but in outdoor extremely high temperature conditions, there is only one way to achieve the desired cooling effect [7], and this method remains difficult. At present, a "wet curtain fan" is usually used in greenhouses and livestock houses. The principle is that negative pressure is formed in the room through the fixed installation of the fan, and the external air enters the greenhouse after cooling through a wet pad, so as to achieve the effect of cooling [10-12]. However, due 
to the small wind power of a traditional axial-flow fan, the effect is not significant enough for use in large-scale cooling. In addition, due to its working principle, it is not suitable for outdoor refrigeration. To achieve wide coverage of cooling outdoors, effective fans should be integrated with evaporative cooling technology. With higher airflow pressure and higher wind speed, tiny droplets evaporate more quickly and the airflow can reach further. Compared with traditional pad-fan cooling, spray evaporation was proven to be better in terms of the cooling efficiency and the maximum cooling rate [13].

The movement of droplets mainly depends on the flow of air, so the performance of the jet fan is key to the cooling effect. According to the investigation, there are a limited number of reports on this cooling technology. In the United States, "Sub Air systems" and "Precision USA" are two companies specializing in the production of cooling fans for golf green lawns, with the brands of "Turf Breeze" and "Breeze Master", respectively (Figure 1). This cooling fan is mainly used in golf green lawn cooling. It is not suitable for gardening establishments with a high plant canopy, it has no spray system, and its cooling effect is still limited. In China, Greenman Machinery Company developed a fan designed for cooling green lawns, but its cooling coverage is smaller and has no spray. Dust-removal fans with sprays are also available to deliver the air and spray at longer distances. However, its spray droplets are too large to achieve the expected cooling effect.

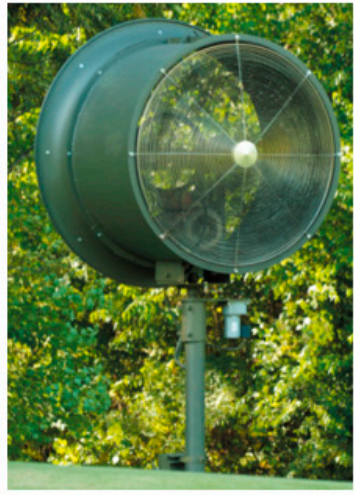

(a)

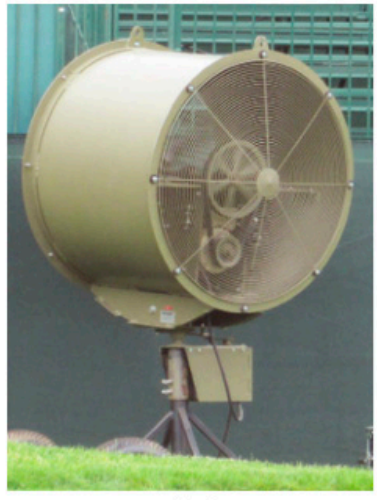

(b)

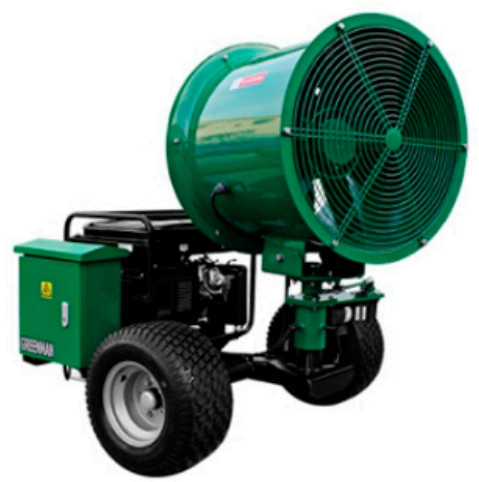

(c)

Figure 1. Cooling fans for green lawns. (a)_Turf Breeze; (b) - Breeze Master; (c)—Greenman.

Spraying parameters are key to cooling effects. Farnham et al. tested the effect of droplet size on cooling effect. The results show that the cooling effect is more obvious when the droplet size is less than $45 \mu \mathrm{m}$. With this droplet size, the cooling effect decreased, the environment became humid, and the comfort of the human body decreased [14].

It is very difficult to directly measure the cooling effect inside the spray due to the direct contact between the sensor and droplet [14]. Computational fluid dynamics (CFD) technology is being increasingly used in the domain of fluid field, heat, and mass transfer analysis [15-18]. Sureshkumar et al. established a two-way coupling model of heat and mass transfer between droplets and air, simulated the heat and mass transfer process between droplets and ambient air, and obtained results consistent with the experimental results, which provided a reference for using CFD technology to simulate water mist cooling $[19,20]$.

This study aims to design a portable spray cooling fan for a tea field based on CFD technology. The spraying droplets are transported to the target cooling area under the wind force to decrease the air temperature (Figure 2). Response surface methodology (RSM) is used to optimize the structural parameters of the airduct, and the spray parameters are optimized by an orthogonal test to improve the cooling effect. 


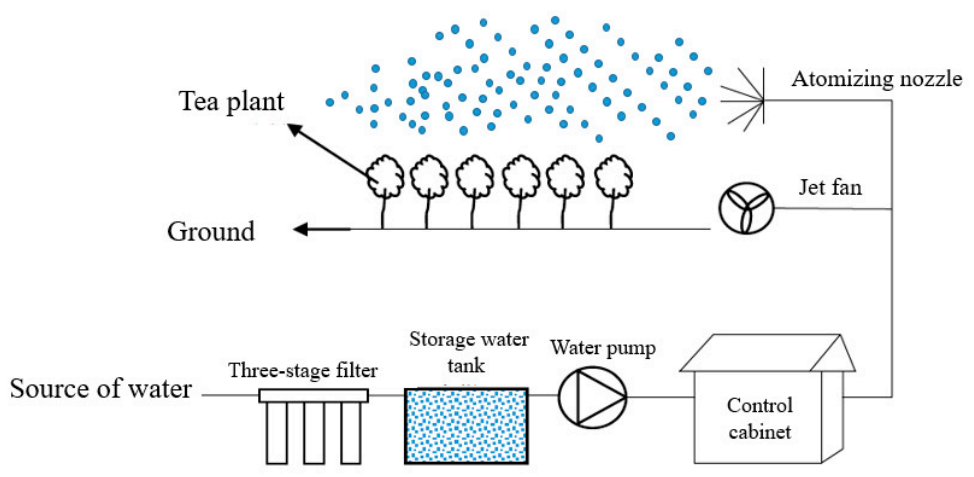

Figure 2. Schematic design and working principle of spray cooling fan.

\section{Materials and Methods}

\subsection{General Composition and Working Principle of Spray Cooling Fan}

A spray cooling fan system is mainly composed of a jet fan, high-pressure plunger pump, atomizing nozzle, control system, water tank, filter, and gasoline generating set (Figure 3). The water is atomized through the high-pressure plunger pump and nozzle, and then the air field provided by the jet fan is used to transport the droplets to the cooling area. The droplets will evaporate and absorb heat to reduce the ambient temperature. In order to prevent nozzle clogging, the water passes through a three-stage filter before entering the high-pressure plunger pump. A gasoline generator set is used to provide the power for the system. The spray cooling fan can be moved to different positions for spray cooling with the manual or trailer.

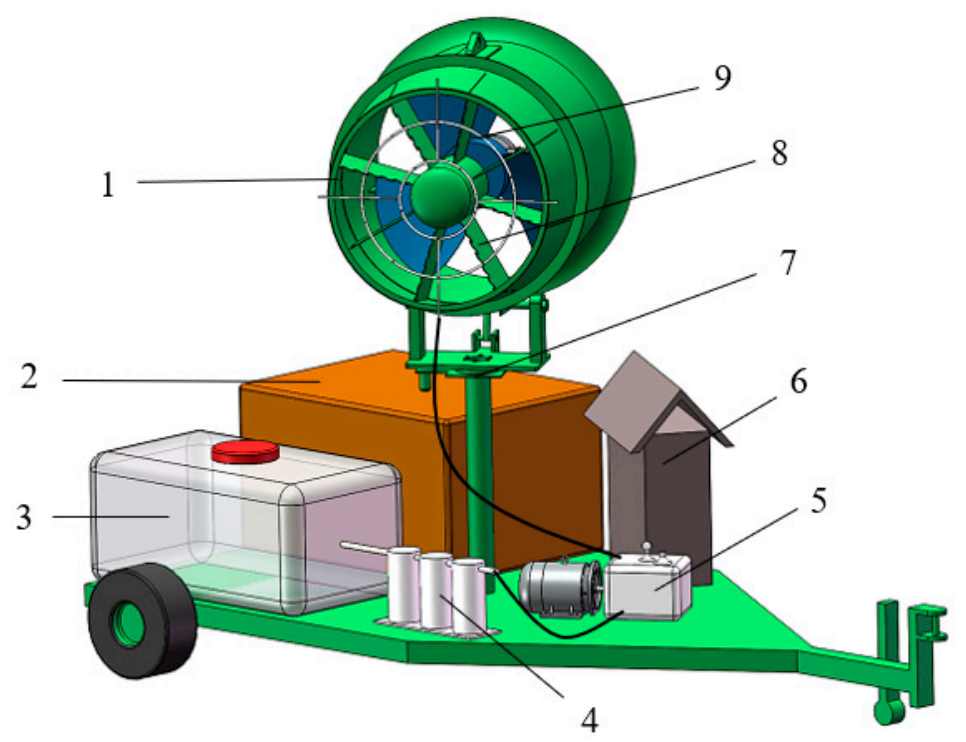

Figure 3. Spray cooling system. 1-Air duct; 2-Gasoline generator set; 3-Water tank; 4-3-stage filter; 5-High-pressure plunger pump; 6-Control system; 7-Crank rocker mechanism; 8-Guide vane; 9-Spray ring.

\subsection{Structure Design of Air Duct}

Table 1 shows the basic parameters of the selected circular arc plate blade. The air duct is designed as a combination of a cylindrical duct and conical duct. The inner diameter of the cylindrical air duct is $1070 \mathrm{~mm}$, and 8 guide vanes are set in the conical air duct to convert the rotating speed contained in the moving airflow into axial speed, eventually improving the thrust and wind range of the fan. The structure type of the air duct is shown in Figure 4. 
Table 1. Basic parameters of circular arc plate blade.

\begin{tabular}{ccccc}
\hline $\begin{array}{c}\text { Installation Angle } \\
\left({ }^{\circ}\right)\end{array}$ & $\begin{array}{c}\text { Swept Angle } \\
\left({ }^{\circ}\right)\end{array}$ & Hub Ratio & $\begin{array}{c}\text { Number of } \\
\text { Leaves }\end{array}$ & $\begin{array}{c}\text { Rotation Diameter } \\
(\mathbf{m m})\end{array}$ \\
\hline 18 & 86 & 0.29 & 3 & 1040 \\
\hline
\end{tabular}

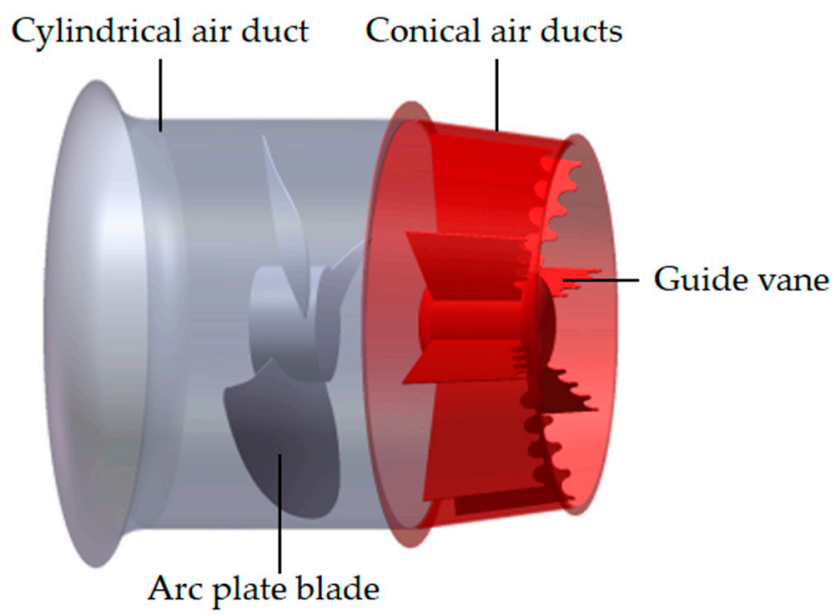

Figure 4. Overall structural design of the air duct.

\subsection{Key Parameter Optimization of Air Duct Based on CFD Simulation}

Air duct structure is the key factor affecting the performance of the jet fan [21], and the exact size parameters of the air duct are difficult calculate. CFD is used to simulate the flow field in the air duct. The influence of the key parameters of the air duct on the performance of the jet fan was analyzed to select the optimal parameter combination.

\subsubsection{Basic Governing Equation}

In fluid mechanics, when the Mach number is less than 0.3 , it is considered incompressible flow [22]. In this study, the maximum velocity of airflow under the action of the jet fan is $53 \mathrm{~m} / \mathrm{s}$, and the maximum Mach number calculated by Equation (1) is 0.16. Therefore, air is considered incompressible.

$$
M_{a}=\frac{v}{c}
$$

where $v$ is the wind speed, $\mathrm{m} / \mathrm{s} ; c$ is the speed of sound, $340 \mathrm{~m} / \mathrm{s}$.

An RNG $k-\varepsilon$ turbulence model was used to solve the Reynolds average N-S equation (RANS) and close the model [23]. It satisfied the mass conservation equation, momentum conservation equation, and energy conservation equation. Its general form is as follows [24]:

$$
\frac{\partial(\rho \varphi)}{\partial t}+\frac{\partial\left(\rho v_{j}\right)}{\partial x_{j}}=\frac{\partial}{\partial x_{j}}\left(\Gamma_{\varphi} \frac{\partial \varphi}{\partial x_{j}}\right)+S_{\varphi}+S_{p \varphi}
$$

where $\varphi$ is the general dependent variable; $\Gamma_{\varphi}$ is the generalized diffusion flux; $S_{\varphi}$ is the gas-phase source term and $S_{p \varphi}$ is the source term produced by the gas-liquid twophase interaction.

\subsubsection{Meshing and Computing Method}

The jet fan is divided into four parts: inlet air domain, rotating domain, air outlet domain, and cone diversion domain. The jet fan model is meshed by a hybrid meshing method [25]. The blades and guide vanes in the model are divided by unstructured grids with good adaptability, and structured grids are used for other areas without complex structures. The multiple reference frame (MRF) model is used to simulate the blade 
rotation [26], and the rotating speed is $960 \mathrm{r} / \mathrm{pm}$. Grid numbers of 0.5 million, 1 million, 1.5 million, 2.0 million, 2.5 million, and 3.0 million were used for numerical simulation to verify the grid's independence. When the total number of grids reached 2 million, the wind speed showed no change (Figure 5b). Therefore, the 2 million order of magnitude grids were used for simulation. The pressure velocity discrete method uses the SIMPLE algorithm $[27,28]$. After initializing the flow field, the calculation was performed, and the convergence standard was set to be less than $10^{-5}$ for each residual item. The results of mesh generation are shown in Figure 5.

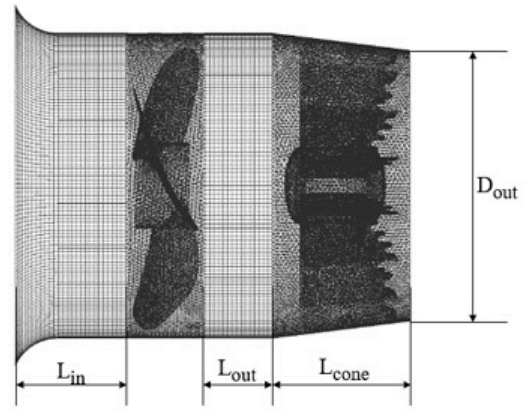

(a)

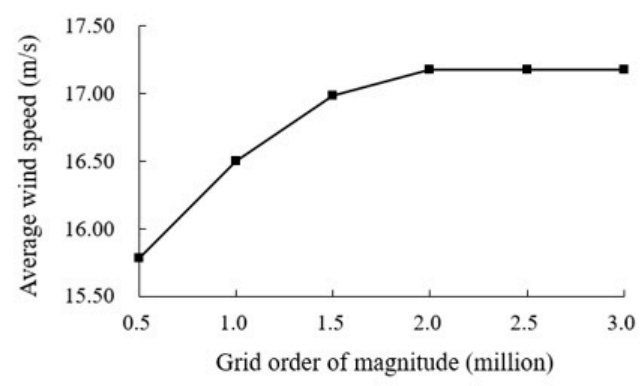

(b)

Figure 5. Mesh generation results and mesh independence verification. (a)-Meshing results; (b) Grid independence verification results.

\subsubsection{Performance Indicator of Jet Fan}

As a special type of axial flow fan, the starting point of the aerodynamic design of a jet fan is different from that of an ordinary axial flow fan. An ordinary axial flow fan mainly requires flow and total pressure, while a jet fan mainly requires thrust. Thrust is defined as the momentum change between the inlet and outlet of the fan-that is, the product of mass flow and average speed [29]:

$$
F=Q_{m} C_{m}=\frac{\rho Q_{v}^{2}}{A}
$$

where $F$ is the thrust of the jet fan; $Q_{m}$ is the mass flow of the jet fan; $c_{m}$ is the average mass speed of the fan; $\rho$ is the air density; $Q_{v}$ is the volume flow of the jet fan; $A$ is the outlet cross-sectional area of the jet fan.

\subsubsection{RSM Experimental Design}

RSM was used to optimize the experimental conditions by performing multiple quadratic regression fitting on the experimental results and establishing the response surface, contour lines, and the influence of single factors on the experimental indicators [30-32]. The indicator value under each factor combination could be easily calculated. Based on the response values of the experimental results of each group, the optimal results and factor combinations could be predicted. According to the basic parameters and practical application of the circular arc plate blade, the length of inlet section $L_{i n}$, outlet section $L_{\text {out }}$, cone section $L_{\text {cone }}$, and outlet diameter of air duct $D_{\text {out }}$ were selected as the influencing factors, and the fan outlet thrust $F$ was taken as the indicator. In total, 29 groups of experiments were conducted according to the central combination principle. Table 2 show the coding of factor levels. 
Table 2. Factor level coding.

\begin{tabular}{ccccc}
\hline \multirow{2}{*}{ Level } & \multicolumn{4}{c}{ Factors } \\
\cline { 2 - 5 } & $\boldsymbol{L}_{\text {in }} \mathbf{( m m )}$ & $\boldsymbol{L}_{\text {out }}(\mathbf{m m})$ & $\boldsymbol{L}_{\text {cone }}(\mathbf{m m})$ & $\boldsymbol{D}_{\text {out }}(\mathbf{m m})$ \\
\hline-1 & 100 & 100 & 200 & 800 \\
0 & 250 & 250 & 350 & 900 \\
1 & 400 & 400 & 500 & 1000 \\
\hline
\end{tabular}

\subsection{Optimization of Spray Parameters Based on Multiphase Flow Simulation}

The essence of spray cooling is to use the evaporation and heat absorption principle of droplets, so the technical parameters of spraying are the key factors affecting the cooling effect. In this study, a tea plantation was taken as the simulation object. A numerical simulation model of spray cooling multiphase flow in the local environment of the tea plantation was established. The spray flow, droplet size, droplet initial temperature, and nozzle layout were studied and optimized by an orthogonal test.

\subsubsection{Construction of Mathematical Model} Species Transport Model

The continuous phase medium was air, which is described as a mixed gas containing oxygen, water vapor, and nitrogen. The component transportation model was used to describe the convection and diffusion of each component. The mass fraction of oxygen in the air was $23 \%$, the mass fraction of water vapor was calculated based on the average relative humidity in the tea field, and the rest was nitrogen [33].

Discrete Phase Model

A discrete phase model (DPM) model can accurately calculate particle trajectories, heat/mass transfer caused by particles, particle evaporation, and condensation when the particle phase volume fraction is less than $10 \%$. With the coordinate method, a droplet group incident source on the outlet surface of the fan was created according to the nozzle position, and the spray flow rate, droplet size, and droplet initial temperature were defined for the phase change model.

FLUENT predicts the trajectory by integrating the force balance on the discrete phase droplets. The force can be described in the Lagrangian coordinate system. The force balance equation is shown in Equation (4) [34]:

$$
m_{p} \frac{d \vec{u}_{p}}{d t}=m_{p} \frac{\vec{u}-\vec{u}_{p}}{\tau_{r}}+m_{p} \frac{\vec{g}\left(\rho_{p}-\rho\right)}{\rho_{p}}+\vec{F}
$$

where $m_{p}$ is the particle mass; $\vec{u}$ is the continuous phase velocity; $\vec{u}_{p}$ is the particle velocity; $\rho$ is the continuous phase density; $\rho_{p}$ is the density of the particles; $\vec{F}$ is the additional force; $m_{p} \frac{\vec{u}-\vec{u}_{p}}{\tau_{r}}$ is the particle resistance, and $\tau_{r}$ is the relaxation time of the particle:

$$
\tau_{r}=\frac{\rho_{p} d_{p}^{2}}{18 \mu} \frac{24}{C_{d} R e}
$$

where $\mu$ is the molecular viscosity of the continuous phase, $d_{p}$ is the particle diameter, and $R e$ is the relative Reynolds number, which is defined as Equation (6):

$$
\operatorname{Re}=\frac{\rho d_{p}\left|\vec{u}_{p}-\vec{u}\right|}{\mu}
$$




\section{Porous Media Model}

The porous media model can be used to define a porous media area, set its porosity, and determine the coefficients of viscosity resistance and inertial resistance for the airflow field. Therefore, the tea tree row can be set as a porous media model, and the influence of the tea tree row on the flow field can be simulated by defining the viscous resistance coefficient, inertial resistance coefficient, and porosity of the porous media area. In the FLUENT software, the processing method for porous media is to add a momentum source term to the momentum equation to simulate the effect of porous media. This source term consists of two parts, the viscous loss term and inertial loss term, which are the two items at the right end of Equation (7) $[35,36]$.

$$
S_{i}=-\left(\sum_{j=1}^{3} D_{i j} \mu v_{j}+\sum_{j=1}^{3} C_{i j} \frac{1}{2} \rho|v| v_{j}\right)(i=x, y, z)
$$

where $S_{i}$ is the source term of momentum equation in the $i(x, y, z)$ direction; $D_{i j}$ is the viscous loss coefficient matrix, and $C_{i j}$ is the inertia loss coefficient matrix.

This negative momentum source term causes a pressure drop in the porous medium region. The tea can be considered homogeneous and isotropic, and the homogeneous porous medium can be simplified as Equation (8):

$$
\mathrm{S}_{i}=-\left(\frac{\mu}{\alpha} v_{i}+C_{2} \frac{1}{2}|v| v_{i}\right)
$$

where $\alpha$ is the permeability; $C_{2}$ is the inertia resistance coefficient-in this case, the matrix $D_{i j}$ is $\frac{1}{\alpha}$, which is the viscous resistance coefficient.

The Kozeny equation can be used to calculate the size of crop canopy permeability. Sase et al. studied the permeability of a tomato canopy through experiments and verified the accuracy of this equation. Therefore, this equation was used to calculate the permeability of the tea canopy:

$$
\alpha=\frac{d_{p}^{2} \times \varepsilon}{180 \times(1-\varepsilon)^{2}}
$$

where $d_{p}$ is the average diameter of tea leaves, which is $0.05 \mathrm{~m}$; $\varepsilon$ is the porosity of the tea canopy, which is 0.89 ; according to Equation (8), the permeability of the tea canopy is $0.00102 \mathrm{~m}^{2}$ and the viscous resistance coefficient of the tea canopy $C_{1}=1 / \alpha=980.39$.

The inertia resistance coefficient of tea can be obtained from Equation (10):

$$
C_{2}=\frac{3.5 \times(1-\varepsilon)}{d_{p} \times \varepsilon^{3}}=9.6
$$

\section{Radiation Model}

Because solar radiation is the main heat source for a tea field's microclimate under high temperatures in summer, the influence of solar radiation should be considered in the simulation process. The solar ray tracing method in FLUENT software was used to add solar radiation as the heat source into the calculation domain [37]. According to the geographical location and orientation of the tea field, the longitude and latitude, time zone, orientation, and other parameters were input.

\subsubsection{Physical Model and Mesh Generation}

A 3D model of the tea field was established to simulate the microclimate environment (Figure 6). The tea tree row was simplified into a rectangular parallelepiped with a length of $40 \mathrm{~m}$, a width of $1 \mathrm{~m}$, and a height of $0.8 \mathrm{~m}$, with a row spacing of $0.6 \mathrm{~m}$. The spray cooling system was located at the end of the row, the fan was $1.5 \mathrm{~m}$ above the ground, and it was working horizontally. Our previous work showed that the calculation results 
would not change when the length of the model was above $60 \mathrm{~m}$. Therefore, the external calculation domain was simplified as a cuboid with a length of $60 \mathrm{~m}$, a width of $10 \mathrm{~m}$, and a height of $5 \mathrm{~m}$.

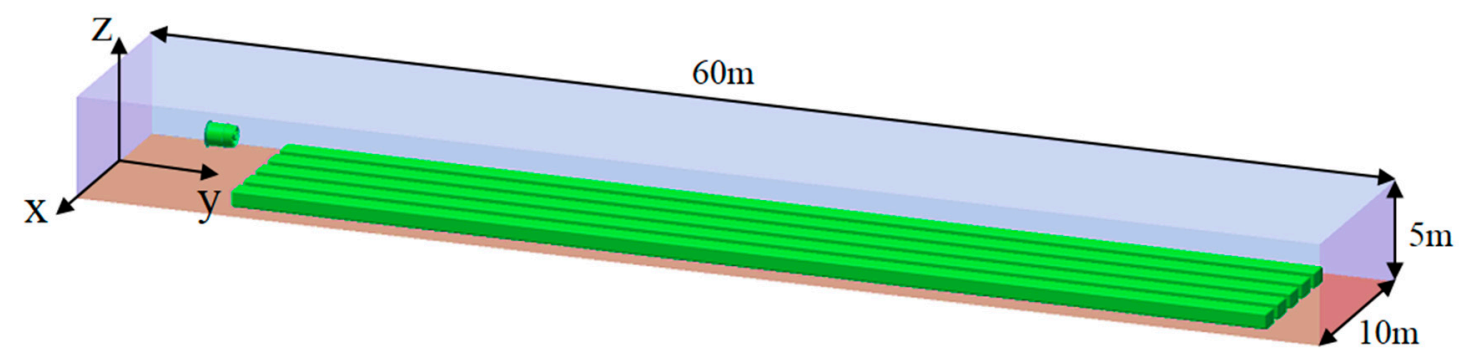

Figure 6. Simulation physical model.

Due to the complexity of the jet fan model, unstructured grids were used for grid division. In this paper, the jet fan, tea row, and other areas with complex structures were treated with local mesh refinement. Then, the grid independence of 3.0 million, 3.5 million, 4.0 million, 4.5 million, 5.0 million, and 5.5 million grids was verified. The wind speed on the outlet surface of the fan and the temperature at $36.0 \mathrm{~m}$ away from the fan were selected as the indicators. When the number of grids exceeded 4.0 million orders of magnitude, the wind speed at the outlet of the fan and the temperature at $36.0 \mathrm{~m}$ away from the fan no longer displayed obvious changes (Figure 7). Therefore, the grid of 4.0 million orders of magnitude was used for the following simulation work (Figure 8).

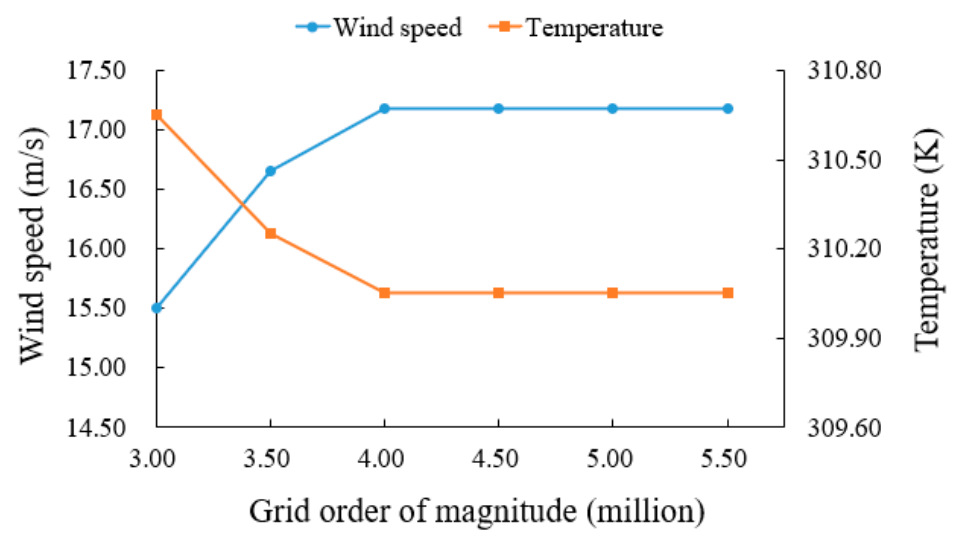

Figure 7. Grid independence verification results.

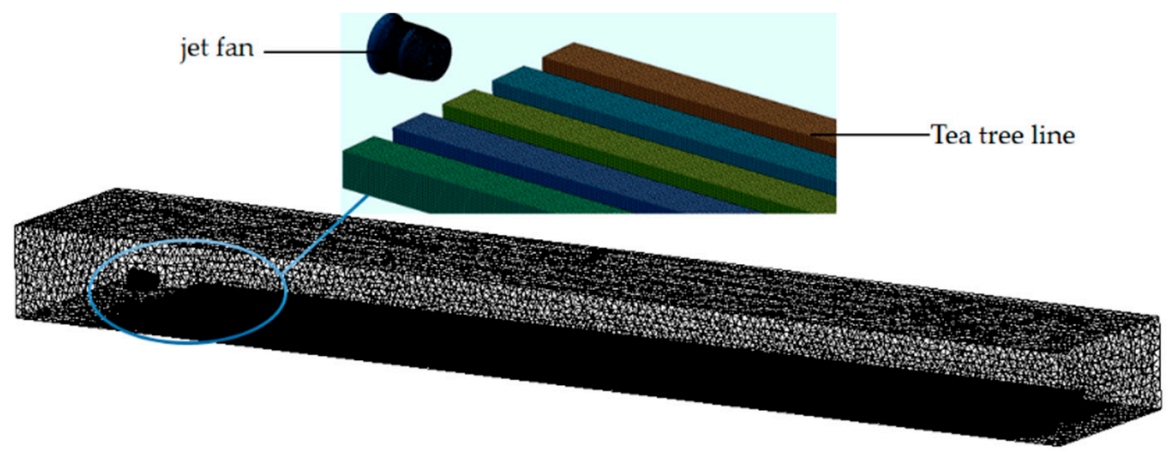

Figure 8. Grid generation results. 


\subsubsection{Boundary Conditions and Calculation Settings}

Since the cooling system was intended for outdoor operation, the inlet of the cuboid was set as the pressure inlet, the relative pressure was set to 0 , and the inlet air temperature was set to $313 \mathrm{~K}$; the other sides and the top were set as the pressure outlet, the relative pressure was set to 0 ; the reflux temperature was set to $313 \mathrm{~K}$; the ground was set as the fixed wall; the impeller part of the fan was set as the rotating wall, and the speed was $960 \mathrm{rpm}$. An interface was established among the different computational domains for data transmission.

\subsubsection{Orthogonal Experimental Design}

In order to study the influence of droplet size, spray mass flow rate, initial droplet temperature, and nozzle layout on the cooling effect and to determine the optimal spray parameters, a standard orthogonal table $L_{9}\left(3^{4}\right)$ was used to conduct 9 groups of experiments [38]. Taking the maximum cooling coverage and cooling distance as indicators, the range analysis of the test results was carried out, and the optimal combination was selected. The factor level table is shown as Table 3. The number of nozzles was set to 15 to achieve the specified spray rate and to minimize the influence of nozzle layout on the fan flow field. Three nozzle layouts were designed (Figure 9).

Table 3. Levels of orthogonal experimental factors.

\begin{tabular}{ccccc}
\hline \multirow{2}{*}{ Levels } & \multicolumn{4}{c}{ Factors } \\
\cline { 2 - 5 } & $\boldsymbol{D}_{\boldsymbol{d}}(\boldsymbol{\mu \mathrm { m } )}$ & $\boldsymbol{Q}_{\boldsymbol{m}} \mathbf{( \mathbf { k g } / \mathbf { m i n } )}$ & $\boldsymbol{T}_{\boldsymbol{i}} \mathbf{( K )}$ & Nozzle Layout \\
\hline 1 & $15-45$ & 2.5 & 288.15 & $\mathrm{a}$ \\
2 & $45-75$ & 3.5 & 298.15 & $\mathrm{~b}$ \\
3 & $75-105$ & 4.5 & 308.15 & $\mathrm{c}$ \\
\hline
\end{tabular}

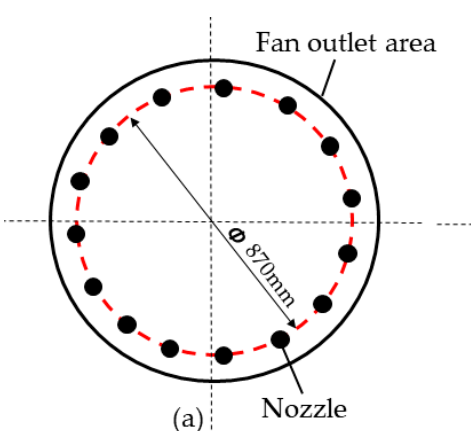

(a)

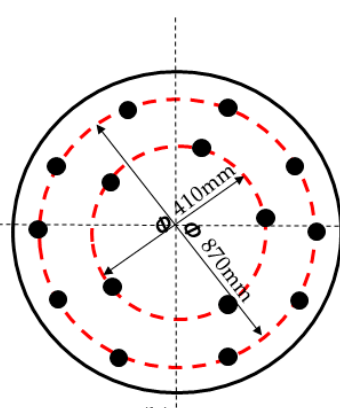

(b)

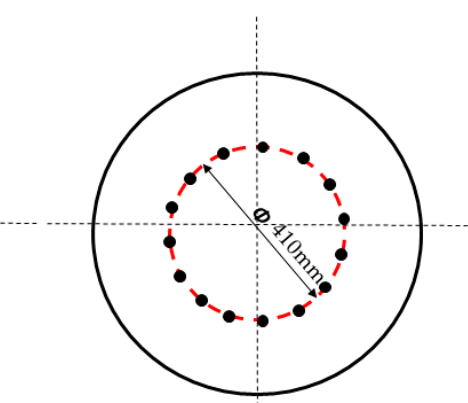

(c)

Figure 9. Three layouts of nozzles. (a)—Large diameter single circle; (b)—Double loop; (c)—Small diameter single circle.

\subsection{Field Test of Spray Cooling Fan}

\subsubsection{Performance Test of Jet Fan}

An anemometer was used to test the wind speed at different test points on the outlet surface of the jet fan (Figure 10). Five sets of tests were averaged as the wind speed value of this test point. The average wind speed of all test points was taken as the average wind speed on the outlet surface of the jet fan. The thrust of the jet fan was calculated by Equation (3). Then, the simulated values of wind speed and thrust were compared with the experimental values. 


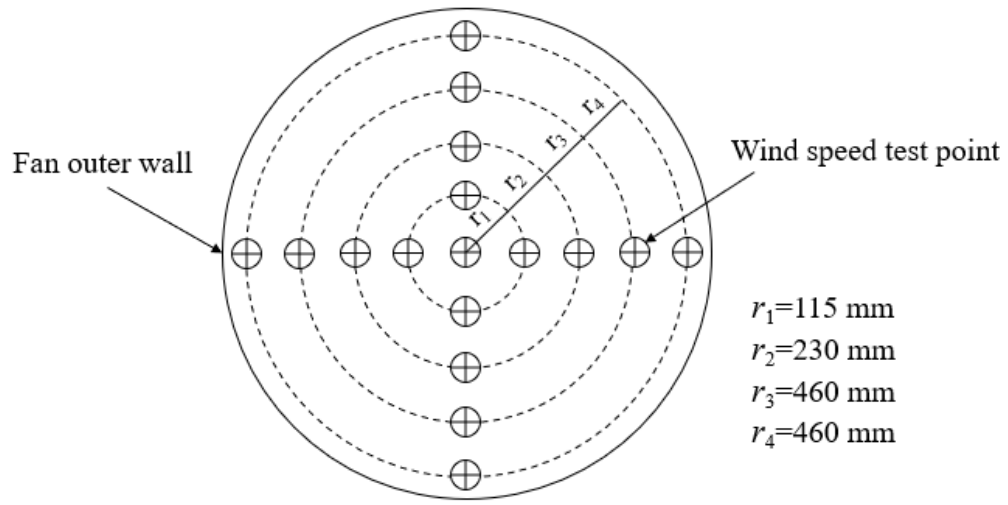

Figure 10. Schematic diagram of wind speed test points on fan outlet surface.

\subsubsection{Effect of Spray Cooling on Tea Fields}

According to the optimization results of droplet parameters, the ceramic three-stage high-pressure atomizer (Wujing, Nantong, China) was selected. When the spray pressure was $5 \mathrm{MPa}$, the nozzle with a diameter of $0.5 \mathrm{~mm}$ and $0.4 \mathrm{~mm}$ produced droplets with a diameter of $15-45 \mu \mathrm{m}$. The spray flow rate of the $0.5 \mathrm{~mm}$ nozzle was $0.321 \mathrm{~kg} / \mathrm{min}$, and the nozzle diameter of $0.4 \mathrm{~mm}$ had a rate of $0.251 \mathrm{~kg} / \mathrm{min}$. Therefore, 10 nozzles of $0.5 \mathrm{~mm}$ aperture and 5 nozzles of $0.4 \mathrm{~mm}$ aperture were selected to make a combined arrangement, which met the requirements of particle size and airflow.

A ZDR-3WIS temperature recorder (Zeda, Hangzhou, China) was used to measure the air temperature. The recorders were set every $6 \mathrm{~m}$ along the air outlet of the fan. In the preparation test, we found that the cooling distance was around $36.0 \mathrm{~m}$. This was because, in the actual test process, the influence of wind, temperature changes, and other environmental factors could not be completely controlled. In particular, in locations furthest from the fan, the influence of the breeze on the droplet trajectory was more serious. Therefore, in the formal test, the maximum distance of the temperature test point was set to $36.0 \mathrm{~m}$. The collection interval of the recorder was 10s. All probes were placed in the radiation shield to prevent measurement error caused by radiation and droplet contact (Figure 11).

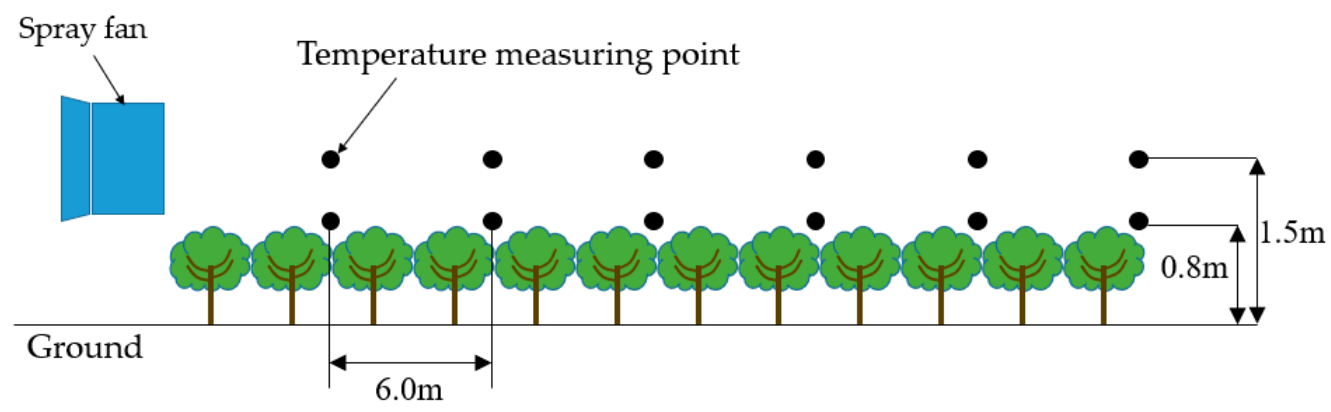

Figure 11. Schematic diagram of temperature test points layout.

The specific test steps were as follows:

1. The spray cooling system was moved to the front end of the tea tree row, and the center line of the jet fan was $1.5 \mathrm{~m}$ high above ground.

2. The temperature recorders were initiated $10 \mathrm{~min}$ before testing the temperature distribution of the tea field.

3. In the period of high temperature without wind, the jet fan and atomization system were initiated at the same time, the pressure of the high-pressure plunger pump was set to $5 \mathrm{MPa}$. 
4. According to the preliminary test results, the continuous operation time was set to 6.0 min to ensure the stability of air temperature.

5. After the system closed, the temperature recorder was collected for data analysis.

\section{Results and Discussion}

\subsection{Simulation Results and Analysis of Airflow Field in Air Duct}

\subsubsection{Results of RSM Experiment}

The response surface experiment combination and results are shown in Table 4 . In order to explore the influence significance between factors and indicators and the influence law of each factor on indicators, the test results were analyzed by variance analysis and two factor effect analysis.

Table 4. RSM experiment combination and results.

\begin{tabular}{|c|c|c|c|c|c|}
\hline \multirow{2}{*}{$\begin{array}{c}\text { Experiment } \\
\text { Number }\end{array}$} & \multicolumn{4}{|c|}{ Factors } & \multirow{2}{*}{$\begin{array}{c}\text { Indicator } \\
\text { Thrust (N }\end{array}$} \\
\hline & $L_{i n}$ & $L_{\text {out }}$ & $L_{\text {cone }}$ & $L_{\text {out }}$ & \\
\hline 1 & 0 & 0 & -1 & 1 & 211.81 \\
\hline 2 & 0 & -1 & 0 & 1 & 206.88 \\
\hline 3 & -1 & 0 & 0 & 1 & 192.37 \\
\hline 4 & 0 & 0 & 0 & 0 & 216.49 \\
\hline 5 & 0 & 1 & -1 & 0 & 219.32 \\
\hline 6 & 0 & -1 & 1 & 0 & 224.21 \\
\hline 7 & 0 & 0 & 1 & -1 & 179.21 \\
\hline 8 & 0 & -1 & 0 & -1 & 184.51 \\
\hline 9 & 0 & 0 & 1 & 1 & 214.48 \\
\hline 10 & 1 & 1 & 0 & 0 & 219.64 \\
\hline 11 & 0 & 0 & 0 & 0 & 216.49 \\
\hline 12 & 0 & 0 & -1 & -1 & 187.38 \\
\hline 13 & -1 & 0 & 1 & 0 & 217.69 \\
\hline 14 & 0 & 1 & 1 & 0 & 217.71 \\
\hline 15 & -1 & 0 & -1 & 0 & 218.54 \\
\hline 16 & 0 & 0 & 0 & 0 & 216.49 \\
\hline 17 & 0 & 1 & 0 & -1 & 187.78 \\
\hline 18 & 0 & 0 & 0 & 0 & 216.49 \\
\hline 19 & 1 & 0 & 0 & -1 & 185.76 \\
\hline 20 & 0 & 0 & 0 & 0 & 216.49 \\
\hline 21 & 1 & 0 & -1 & 0 & 216.20 \\
\hline 22 & -1 & -1 & 0 & 0 & 222.21 \\
\hline 23 & 0 & -1 & 1 & 0 & 211.55 \\
\hline 24 & 1 & -1 & 0 & 0 & 216.15 \\
\hline 25 & 1 & 0 & 0 & 1 & 211.97 \\
\hline 26 & -1 & 1 & 0 & 0 & 221.19 \\
\hline 27 & 0 & 1 & 0 & 1 & 214.11 \\
\hline 28 & 1 & 0 & 1 & 0 & 217.23 \\
\hline 29 & -1 & 0 & 0 & -1 & 183.07 \\
\hline
\end{tabular}

\subsubsection{Variance Analysis}

Table 5 shows the variance analysis of the fan thrust. In the table, A, B, C, and D represent $L_{\text {in }}, L_{\text {out }}, L_{\text {cone }}$, and $D_{\text {out }}$, respectively. Table 5 shows that the $F$-value of the testing was 108.09 , and the $p$-value was less than 0.05 , so the variance was significant. In addition, the diameter of the air outlet was the main factor that affected the thrust of the jet fan, followed by the length of the diversion section. The length of the inlet section and the length of the outlet section had a relatively small effect on the thrust of the jet fan. 
Table 5. Variance analysis of fan thrust.

\begin{tabular}{ccccccc}
\hline Source & Sum of Squares & $\mathbf{d f}$ & Mean Square & $\boldsymbol{F}$-Value & $\boldsymbol{p}$-Value & \\
\hline Model & 5160.12 & 14 & 368.58 & 18.09 & $<0.0001$ & significant \\
$\mathrm{A}$ & 11.76 & 1 & 11.76 & 0.5773 & 0.4600 & \\
$\mathrm{~B}$ & 16.90 & 1 & 16.90 & 0.8295 & 0.3778 & \\
$\mathrm{C}$ & 31.98 & 1 & 31.98 & 1.57 & 0.2308 & \\
$\mathrm{D}$ & 1725.84 & 1 & 1725.84 & 84.71 & $<0.0001$ & \\
$\mathrm{AB}$ & 5.09 & 1 & 5.09 & 0.2496 & 0.6251 & \\
$\mathrm{AC}$ & 0.8836 & 1 & 0.8836 & 0.0434 & 0.8380 & \\
$\mathrm{AD}$ & 71.49 & 1 & 71.49 & 3.51 & 0.0821 & \\
$\mathrm{BC}$ & 30.53 & 1 & 30.53 & 1.50 & 0.2411 & \\
$\mathrm{BD}$ & 3.92 & 1 & 3.92 & 0.1924 & 0.6676 & \\
$\mathrm{CD}$ & 29.38 & 1 & 29.38 & 1.44 & 0.2497 & \\
$\mathrm{~A}^{2}$ & 1.84 & 1 & 1.84 & 0.0904 & 0.7681 & \\
$\mathrm{~B}^{2}$ & 36.50 & 1 & 36.50 & 1.79 & 0.2021 & \\
$\mathrm{C}^{2}$ & 8.29 & 1 & 8.29 & 0.4072 & 0.5337 & \\
$\mathrm{D}^{2}$ & 2825.01 & 1 & 2825.01 & 138.67 & $<0.0001$ & \\
Residual & 285.22 & 14 & 20.37 & & \\
Lack of Fit & 285.22 & 10 & 28.52 & & \\
Pure Error & 0.0000 & 4 & 0.0000 & & \\
Cor Total & 5445.33 & 28 & & & \\
\hline
\end{tabular}

\subsubsection{Analysis of Interaction between Two Factors}

As shown in Figure 12a-d, the fan thrust increased slightly with the $L_{\text {in }}$ and $L_{o u t}$, so the influence of $L_{\text {in }}$ and $L_{\text {out }}$ on the fan thrust was very small. According to Figure $12 \mathrm{~b}, \mathrm{~d}, \mathrm{f}$, $L_{\text {cone }}$ had little effect on the thrust of the fan. As the $L_{\text {cone }}$ increased, the fan thrust had a slow downward trend. According to Figure 12c,e,f, the influence of $D_{\text {out }}$ on fan thrust was rather obvious. With the increase in $D_{\text {out }}$, the thrust of the fan first increased rapidly and then decreased sharply, so there was an optimal $D_{\text {out }}$ for maximizing the thrust of the fan.

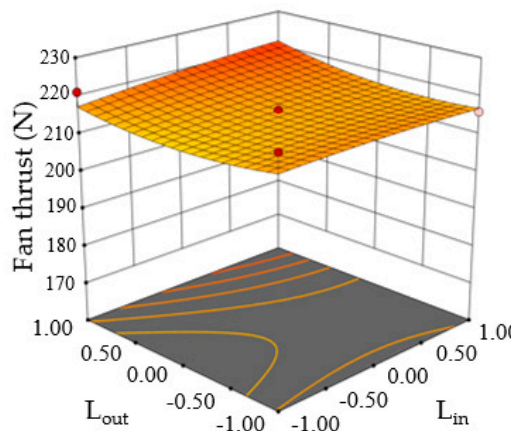

(a)

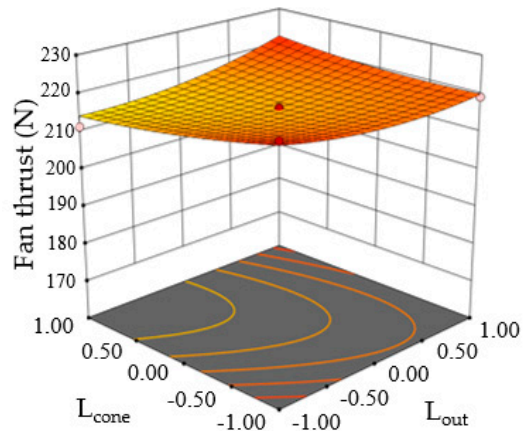

(d)

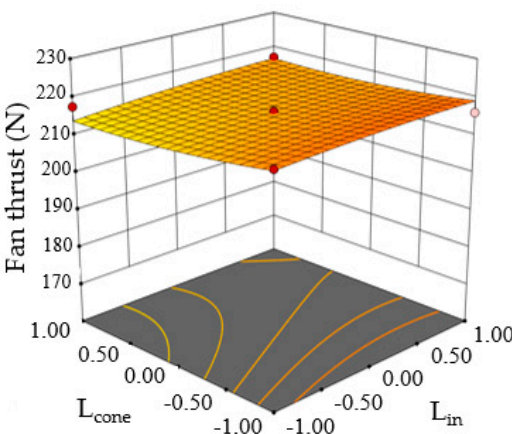

(b)

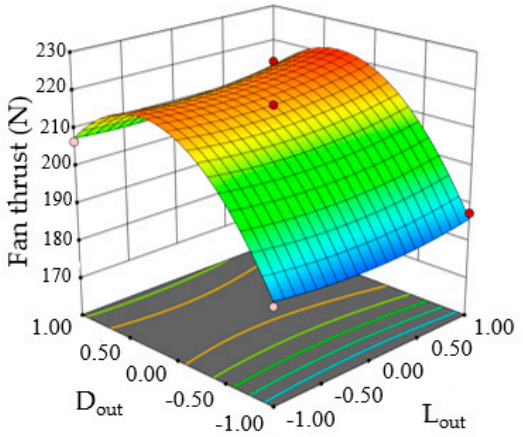

(e)

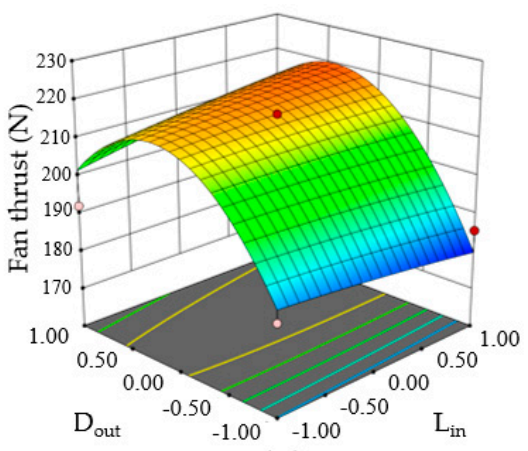

(c)

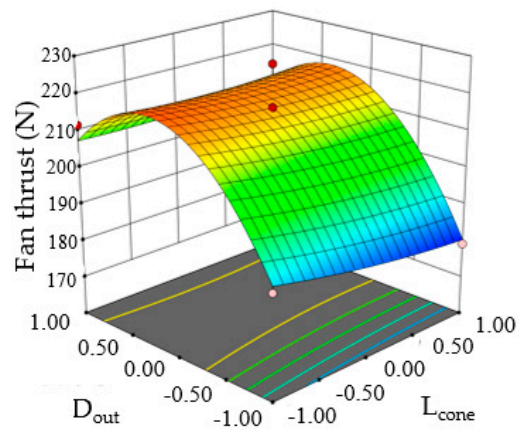

(f)

Figure 12. Two-factor interaction analysis. (a) -Interaction between $L_{i n}$ and $L_{\text {out }} ;$ (b) - Interaction between $L_{c o n e}$ and $L_{i n}$; (c) - Interaction between $L_{\text {in }}$ and $D_{\text {out }} ;(\mathbf{d})$-Interaction between $L_{\text {cone }}$ and $L_{\text {out }} ;(\mathbf{e})$-Interaction between $L_{\text {out }}$ and $D_{\text {out }}$; (f)-Interaction between $L_{\text {cone }}$ and $D_{\text {out }}$. 
Taking the maximum thrust as the indicator, the optimal prediction of different parameter combinations was carried out using Design Expert 12.0 software. The results show that the $L_{\text {in }}$ was $300 \mathrm{~mm}$, the $L_{\text {out }}$ was $300 \mathrm{~mm}$, the $L_{\text {cone }}$ was $450 \mathrm{~mm}$, and the $D_{\text {out }}$ was $950 \mathrm{~mm}$, where the predicted value of fan thrust was $229.12 \mathrm{~N}$, the average wind speed on the fan outlet surface was $17.18 \mathrm{~m} / \mathrm{s}$, and the volume flow was $10.88 \mathrm{~m}^{3} / \mathrm{s}$.

\subsubsection{Simulation Results of Optimized Parameters}

According to the optimized parameters of the air duct, the jet fan was remodeled and meshed for simulation verification, and the simulated value was compared with the predicted value. The comparison results show that the relative errors of the simulated and predicted values of thrust, average velocity, and volume flow were all less than $4 \%$, indicating that the optimization results were reliable (Table 6).

Table 6. The simulated and predicted values and their relative errors.

\begin{tabular}{ccc}
\hline & Thrust (N) & Average Speed (m/s) \\
\hline Optimize predicted value & 229.12 & 17.18 \\
Simulation value & 225.06 & 17.02 \\
Relative error $(\%)$ & 1.8 & 3.9 \\
\hline
\end{tabular}

\subsection{Simulation and Analysis of Spray Cooling for Multiphase Flow}

The CFD-post module of ANSYS was used to calculate the maximum temperature drop (the difference between the initial ambient temperature and the lowest temperature within the computational domain) and effective cooling distance (along the axis of the fan, the distance from the center of the fan outlet surface to the point where the initial temperature changes by at least 1 degree) in the simulation domain (Table 7). The experimental results of temperature drop and effective cooling distance were analyzed. The trend of influence of factors on indicators is shown in Figure 13.

Table 7. Orthogonal experimental results and intuitive analysis.

\begin{tabular}{|c|c|c|c|c|c|c|c|}
\hline & \multirow[b]{2}{*}{ Testing Order Number } & \multicolumn{4}{|c|}{ Factors } & \multicolumn{2}{|c|}{ Indicators } \\
\hline & & A & B & $\mathrm{C}$ & D & $\begin{array}{l}\text { Temperature } \\
\text { Drop }\end{array}$ & $\begin{array}{l}\text { Effective Distance of } \\
\text { Cooling }\end{array}$ \\
\hline & 1 & 1 & 1 & 1 & 1 & 7.5 & 32.01 \\
\hline & 2 & 1 & 2 & 2 & 2 & 10.72 & 38.12 \\
\hline & 3 & 1 & 3 & 3 & 3 & 10.67 & 40.06 \\
\hline & 4 & 2 & 1 & 2 & 3 & 4.18 & 31.81 \\
\hline & 5 & 2 & 2 & 3 & 1 & 5.71 & 35.23 \\
\hline & 6 & 2 & 3 & 1 & 2 & 8.34 & 38.85 \\
\hline & 7 & 3 & 1 & 3 & 2 & 2.93 & 31.40 \\
\hline & 8 & 3 & 2 & 1 & 3 & 3.58 & 34.21 \\
\hline & 9 & 3 & 3 & 2 & 1 & 4.26 & 36.75 \\
\hline \multirow{8}{*}{$\begin{array}{l}\text { Temperature } \\
\text { drop }\end{array}$} & K1 & 28.89 & 14.61 & 19.42 & 17.47 & & \\
\hline & K2 & 18.23 & 20.01 & 19.16 & 21.99 & & \\
\hline & K3 & 10.77 & 23.27 & 19.31 & 18.43 & & \\
\hline & $k 1$ & 9.63 & 4.87 & 6.47 & 5.82 & & \\
\hline & $k 2$ & 6.08 & 6.67 & 6.39 & 7.33 & & \\
\hline & $k 3$ & 3.59 & 7.76 & 6.44 & 6.14 & & \\
\hline & Range & 6.04 & 2.89 & 0.08 & 1.51 & & \\
\hline & $\begin{array}{l}\text { Primary and secondary factors } \\
\text { Optimal solution }\end{array}$ & \multicolumn{4}{|c|}{$\begin{array}{c}\mathrm{ABDC} \\
\mathrm{A}_{1} \mathrm{~B}_{3} \mathrm{C}_{1} \mathrm{D}_{2}\end{array}$} & & \\
\hline \multirow{8}{*}{$\begin{array}{l}\text { Effective } \\
\text { distance of } \\
\text { cooling }\end{array}$} & K1 & 110.19 & 95.22 & 105.07 & 103.99 & & \\
\hline & $\mathrm{K} 2$ & 105.89 & 107.56 & 106.68 & 108.37 & & \\
\hline & K3 & 102.36 & 115.66 & 106.69 & 106.08 & & \\
\hline & $k 1$ & 36.73 & 31.74 & 35.02 & 34.66 & & \\
\hline & $k 2$ & 35.30 & 35.85 & 35.56 & 36.12 & & \\
\hline & $k 3$ & 34.12 & 38.55 & 35.56 & 35.36 & & \\
\hline & Range & 2.61 & 6.81 & 0.54 & 1.46 & & \\
\hline & $\begin{array}{l}\text { Primary and secondary factors } \\
\text { Optimal solution }\end{array}$ & \multicolumn{4}{|c|}{$\begin{array}{c}\text { BADC } \\
\mathrm{A}_{1} \mathrm{~B}_{3} \mathrm{C}_{2 \mathrm{or} 3} \mathrm{D}_{2}\end{array}$} & & \\
\hline
\end{tabular}



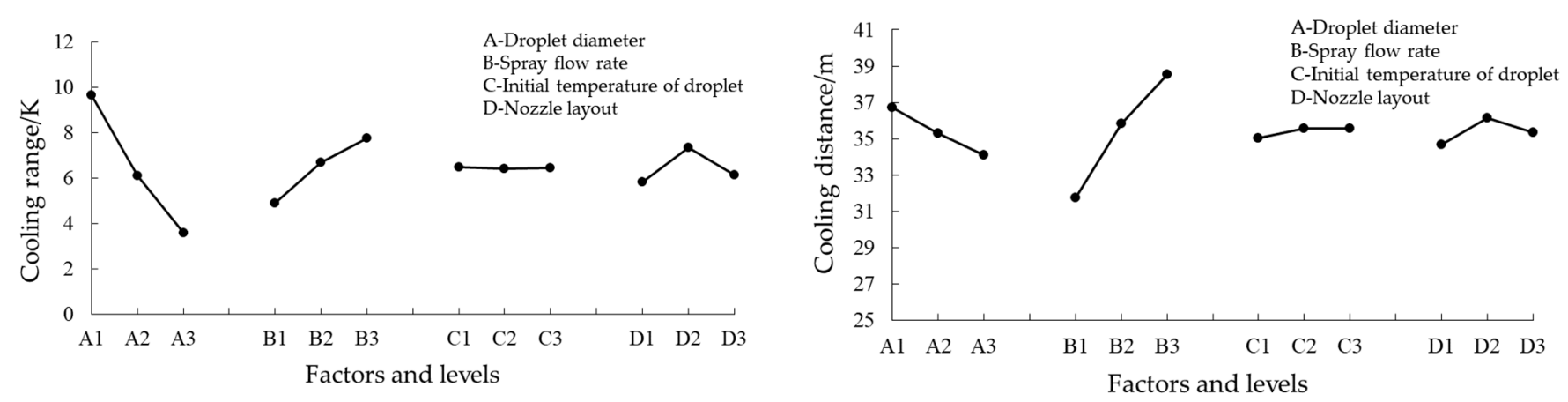

Figure 13. The influence trend chart of various factors on the cooling coverage and cooling distance.

According to the intuitive analysis results, the droplet size had the greatest influence on the cooling coverage, followed by the spray flow, and then the nozzle layout, while the initial droplet temperature had the least influence on the results. The spray flow rate had the greatest influence on the cooling distance, followed by the droplet size and the nozzle layout, while the initial droplet temperature had the least influence on the results.

The comprehensive balance method was adopted to determine the optimal scheme.

First, the optimal level combination of each factor was determined according to the range and indicator trend chart:

- For the maximum temperature drop: $\mathrm{A}_{1} \mathrm{~B}_{3} \mathrm{C}_{1} \mathrm{D}_{2}$;

- For the effective distance of cooling: $\mathrm{A}_{1} \mathrm{~B}_{3} \mathrm{C}_{2}$ or $3 \mathrm{D}_{2}$.

The results show that the optimal levels of droplet size, spray flow, and nozzle layout were consistent for temperature drop and effective distance of cooling. However, the initial temperature of fog drops had very little influence on the temperature drop and effective distance of cooling, so it could be ignored.

The optimal combination of the cooling effect was as follows: a droplet diameter of 15 to $45 \mu \mathrm{m}$, a spray flow of $4.5 \mathrm{~kg} / \mathrm{min}$, nozzles with a double circle layout, and an initial droplet temperature of $298.15 \mathrm{~K}$. Then, the same method was used to simulate and verify the optimal scheme. The simulation results show that the maximum cooling coverage was $11.09 \mathrm{~K}$ and the cooling distance was $42.56 \mathrm{~m}$.

According to Figure 14a, at the height of $1.5 \mathrm{~m}$ above the ground, the temperature in the core cooling area was the lowest and gradually increased towards the surrounding area. This is because a large number of droplets evaporated in the range of 5 to $15 \mathrm{~m}$ in front of the fan, taking more heat away in the core area. The cooling area changed significantly along the row at the height of $0.8 \mathrm{~m}$ due to the blocking effect of the tea canopy (Figure 14b). The cooling coverage and the cooling distance decreased.

\subsection{Field Test Results and Analysis}

\subsubsection{Performance Test Results Analysis of Jet Fan}

According to the optimal structural parameters of the air duct, the motor was directly connected with the blade, and the rotation speed was $960 \mathrm{r} / \mathrm{min}$. After the test at each point, average wind speed on the outlet surface and the thrust of the jet fan were calculated. The relative errors were $2.9 \%$ and $2.8 \%$, respectively, which might have been caused by the environmental wind speed and experimental instruments (Table 8). The relative error was small, so it was reliable to use the optimal results. 


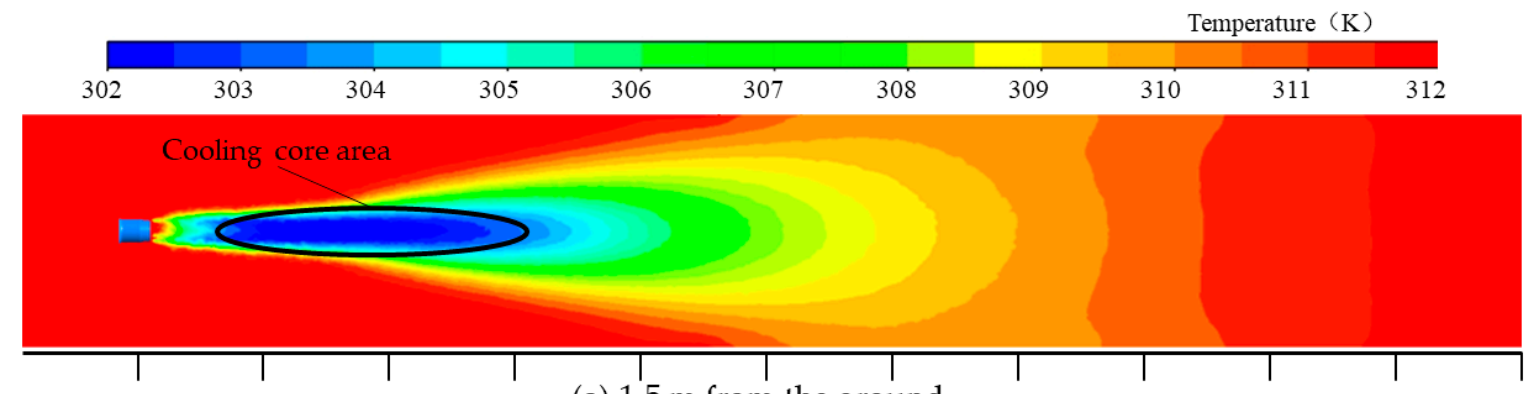

(a) $1.5 \mathrm{~m}$ from the ground

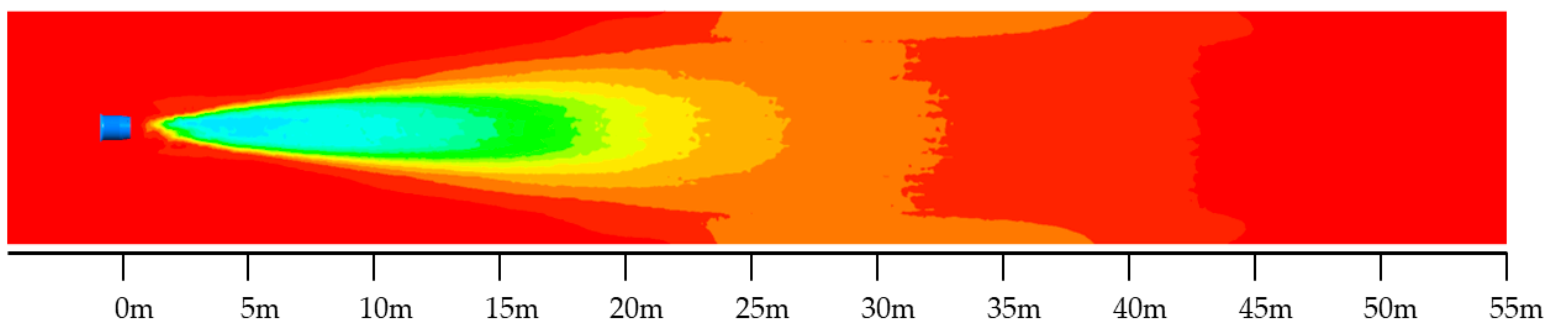

(b) $0.8 \mathrm{~m}$ from the ground

Figure 14. The temperature distribution on the horizontal plane at different heights above the ground. (a)-Temperature distribution on the horizontal plane $1.5 \mathrm{~m}$ above the ground; (b)-temperature distribution on the horizontal plane $0.8 \mathrm{~m}$ above the ground.

Table 8. Comparison of simulated and experimental values.

\begin{tabular}{ccc}
\hline & Wind Speed $(\mathbf{m} / \mathbf{s})$ & Thrust $(\mathbf{N})$ \\
\hline Simulation value & 17.02 & 225.06 \\
Test value & 17.25 & 231.52 \\
Relative error $(\%)$ & 2.9 & 2.8 \\
\hline
\end{tabular}

\subsubsection{Test Result Analysis of Cooling Effect of Spray Cooling Fan}

The experiment was conducted at Yinchun Biya tea farm $\left(32^{\circ} 01^{\prime} 34.27^{\prime \prime} \mathrm{N}, 119^{\circ} 40^{\prime} 26.35^{\prime \prime} \mathrm{E}\right)$ in Danyang City, China, with a high air temperature on 21 July 2020. The sampled tea variety was Maolu, which was 12 years old. The width of the tea tree row was $1.0 \mathrm{~m}$, the distance between the tea tree rows was $0.6 \mathrm{~m}$, and the height of the tea canopy was $0.8 \mathrm{~m}$ (Figure 15).

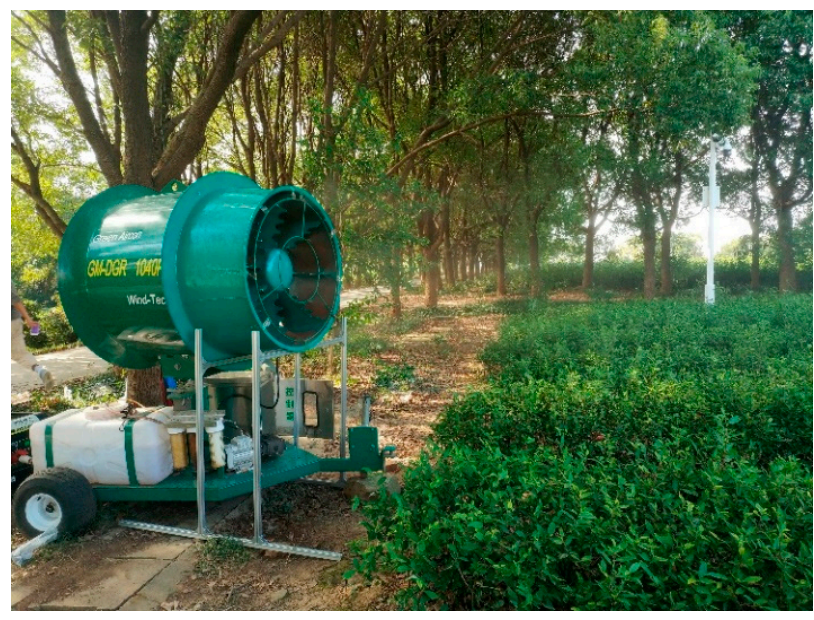

Figure 15. Construction site of spray cooling system.

Figure 16 shows the temperature change at each test point at $1.5 \mathrm{~m}$ height and $0.8 \mathrm{~m}$ height. The whole process was divided into three stages: T1-the spray cooling fan was not 
running (0-1.0 $\mathrm{min})$; T2 — the spray cooling fan started to run (1.0 $\mathrm{min}-7.0 \mathrm{~min})$; T3 - the spray cooling fan stopped (7.0 $\mathrm{min}-15 \mathrm{~min})$.

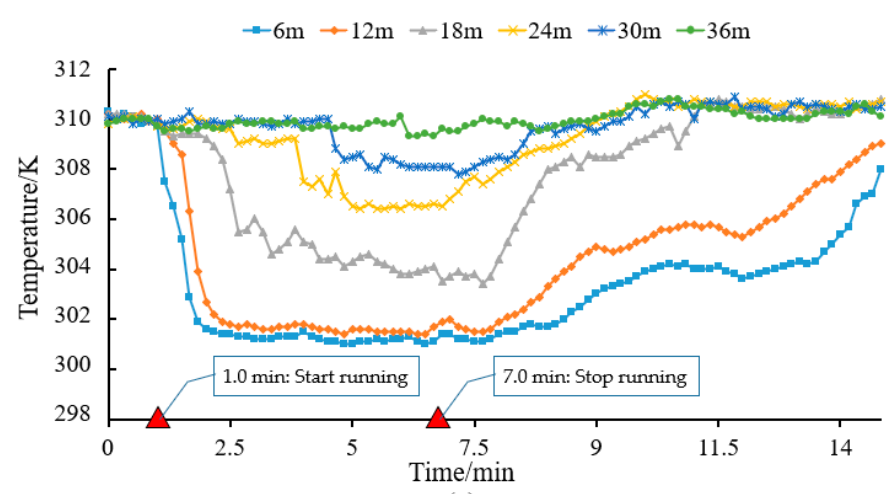

(a)

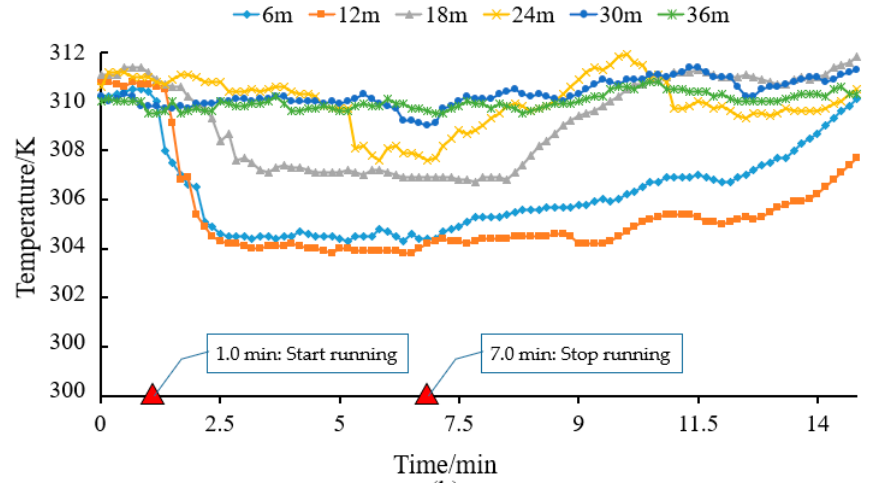

(b)

Figure 16. Temperature change curves of each test point at $1.5 \mathrm{~m}$ height and $0.8 \mathrm{~m}$ height. (a)-Temperature change of each measuring point at $1.5 \mathrm{~m}$ height; (b) - Temperature change of each measuring point at $0.8 \mathrm{~m}$ height.

At the T1 stage, when the spray cooling fan was not operating, the temperature of each test point ranged from $310.05 \mathrm{~K}$ to $310.95 \mathrm{~K}$. At the $\mathrm{T} 2$ stage, after the spray cooling fan started to run, the temperature of each test point decreased, but the range of temperature decrease at different positions was significantly different. At the T3 stage, after the spray cooling fan stopped, the temperature of each test point began to rise again.

Table 9 shows the temperature drop simulation results and test results of 12 test points, and the error range was $0.2 \mathrm{~K}-1.3 \mathrm{~K}$. The error might have resulted from the initial temperature and other environmental factors. The cooling system provided $1.1 \mathrm{~K}-9.1 \mathrm{~K}$ cooling effect within $36.0 \mathrm{~m}$ in front of the fan at the height of $1.5 \mathrm{~m}$, and $0.6 \mathrm{~K}-6.5 \mathrm{~K}$ in the range of $36.0 \mathrm{~m}$ at the height of $0.8 \mathrm{~m}$.

Table 9. Simulation results, test results, and errors of each test point.

\begin{tabular}{|c|c|c|c|c|c|c|c|}
\hline \multirow{2}{*}{ Vertical Height } & \multirow{2}{*}{$\begin{array}{c}\text { Simulation and Experimental } \\
\text { Results (K) }\end{array}$} & \multicolumn{6}{|c|}{ Distance from Fan } \\
\hline & & $6 \mathrm{~m}$ & $12 \mathrm{~m}$ & $18 \mathrm{~m}$ & $24 \mathrm{~m}$ & $30 \mathrm{~m}$ & $36 \mathrm{~m}$ \\
\hline \multirow{3}{*}{$1.5 \mathrm{~m}$} & Simulation results & 10.1 & 10.0 & 7.2 & 4.3 & 3.2 & 1.8 \\
\hline & Test result & 9.1 & 8.7 & 6.3 & 4.1 & 2.1 & 1.1 \\
\hline & Error & 1.0 & 1.3 & 0.9 & 0.2 & 1.1 & 0.7 \\
\hline \multirow{3}{*}{$0.8 \mathrm{~m}$} & Simulation results & 7.1 & 6.9 & 6.1 & 2.1 & 1.5 & 0.8 \\
\hline & Test result & 6.5 & 7.1 & 5.2 & 2.8 & 0.8 & 0.6 \\
\hline & Error & 0.6 & 0.2 & 0.9 & 0.7 & 0.7 & 0.2 \\
\hline
\end{tabular}

However, droplet evaporation could lead to an increase in the air humidity, and humidity would also affect the evaporation, so this technology may not be applied to a high-humidity environment.

\section{Conclusions}

An optimal design of a jet fan and the selection of spray parameters for a tea field were conducted in this research. Although the research results cannot be directly used as a reference for areas with different background conditions, it can provide a new research idea. The main conclusions are as follows.

The structural parameters of a jet fan influence its thrust. For this study, the optimal parameters of the length of the inlet section $L_{i n}$, the length of the outlet section $L_{\text {out }}$, the length of the conical section $L_{c o n e}$, and the diameter of the outlet $D_{\text {out }}$ of the jet fan were 
$300 \mathrm{~mm}, 300 \mathrm{~m}, 450 \mathrm{~mm}$, and $950 \mathrm{~mm}$, respectively, where the thrust of the jet fan reached the maximum value of $225.06 \mathrm{~N}$.

The spray droplet size had the greatest influence on the maximum cooling coverage, and the small droplet size was favorable to improve the coverage. Spray mass flow was also helpful to increase its maximum cooling coverage. However, the initial droplet temperature or nozzle layout had little influence on the maximum cooling coverage.

Spray airflow had the greatest impact on cooling distance, followed by droplet size and nozzle layout. Increasing spray flow and decreasing droplet size are beneficial to increase the cooling distance. The initial temperature of droplet has little effect on the cooling distance.

When ambient temperature was $310.05 \mathrm{~K}-310.95 \mathrm{~K}$, the effective cooling distance of the spray cooling fan was around $36.0 \mathrm{~m}$, and the maximum temperature drop was $9.1 \mathrm{~K}$. With a decrease in vertical height, the cooling effect weakened, and the decrease in the temperature at the height of $1.5 \mathrm{~m}$ above the ground was higher than that at the height of $0.8 \mathrm{~m}$.

CFD simulation technology and RSM experiments could be used to optimize the design of jet fans with low test costs and optimal spray parameters in order to improve their operation.

Author Contributions: Conceptualization, Y.C. and Y.H.; methodology, Y.C. and Y.H.; software, Y.C.; validation, Y.C. and Y.H.; formal analysis, Y.C., Y.H. and W.W.; investigation, Y.C. and Z.H.; resources, Y.H. and P.L.; data curation, Y.C.; writing-original draft preparation, Y.C.; writingreview and editing, Y.C., Y.H. and W.W. All authors have read and agreed to the published version of the manuscript.

Funding: This research was funded by the Priority Academic Program Development of Jiangsu Higher Education Institutions (PAPD-2018-87) and the Key R\&D project of Zhenjiang City, Jiangsu Province (Modern Agriculture) (NY2018007).

Institutional Review Board Statement: Not applicable.

Informed Consent Statement: Not applicable.

Data Availability Statement: Not applicable.

Conflicts of Interest: The authors declare no conflict of interest.

\section{References}

1. Ren, T.; Zheng, P.; Zhang, K.; Liao, J.; Xiong, F.; Shen, Q.; Ma, Y.; Fang, W.; Zhu, X. Effects of GABA on the polyphenol accumulation and antioxidant activities in tea plants (Camellia sinensis L.) under heat-stress conditions. Plant Physiol. Biochem. 2021, 159, 363-371. [CrossRef] [PubMed]

2. Webb, L.; Darbyshire, R.; Goodwin, I. Climate Change: Horticulture. In Encyclopedia of Agriculture and Food Systems; Van Alfen, N.K., Ed.; Academic Press: Oxford, UK, 2014; pp. 266-283.

3. Ahmed, H.A.; Tong, Y.-X.; Yang, Q.-C.; Al-Faraj, A.A.; Abdel-Ghany, A.M. Spatial distribution of air temperature and relative humidity in the greenhouse as affected by external shading in arid climates. J. Integr. Agric. 2019, 18, 2869-2882. [CrossRef]

4. García, M.L.; Medrano, E.; Sánchez-Guerrero, M.C.; Lorenzo, P. Climatic effects of two cooling systems in greenhouses in the Mediterranean area: External mobile shading and fog system. Biosyst. Eng. 2011, 108, 133-143. [CrossRef]

5. Gao, Y.; Shao, S.; Tian, S.; Xu, H.; Tian, C. Energy consumption analysis of the forced-air cooling process with alternating ventilation mode for fresh horticultural produce. Energy Procedia 2017, 142, 2642-2647. [CrossRef]

6. Ulpiani, G. Water mist spray for outdoor cooling: A systematic review of technologies, methods and impacts. Appl. Energy 2019, 254, 113647. [CrossRef]

7. Tai, C.; Sawada, Y.; Masuda, J.; Daimon, H.; Fukao, Y. Cultivation of spinach in hot seasons using a micro-mist-based temperaturecontrol system. Sci. Hortic. 2020, 273, 109603. [CrossRef]

8. Almuhanna, E.A.; Gamea, G.R.; Osman, O.E.; Almahdi, F.M. Performance of roof-mounted misting fans to regulate heat stress in dairy cows. J. Therm. Biol. 2021, 99, 102984. [CrossRef]

9. Sethi, V.P.; Sharma, S.K. Survey of cooling technologies for worldwide agricultural greenhouse applications. Sol. Energy 2007, 81, 1447-1459. [CrossRef]

10. Saberian, A.; Sajadiye, S.M. Assessing the variable performance of fan-and-pad cooling in a subtropical desert greenhouse. Appl. Therm. Eng. 2020, 179, 115672. [CrossRef] 
11. López, A.; Valera, D.L.; Molina-Aiz, F.D.; Peña, A. Sonic anemometry to evaluate airflow characteristics and temperature distribution in empty Mediterranean greenhouses equipped with pad-fan and fog systems. Biosyst. Eng. 2012, 113, 334-350. [CrossRef]

12. Banik, P.; Ganguly, A. Performance and economic analysis of a floricultural greenhouse with distributed fan-pad evaporative cooling coupled with solar desiccation. Sol. Energy 2017, 147, 439-447. [CrossRef]

13. Çaylı, A.; Akyüz, A.; Üstün, S.; Yeter, B. Efficiency of two different types of evaporative cooling systems in broiler houses in Eastern Mediterranean climate conditions. Therm. Sci. Eng. Prog. 2021, 22, 100844. [CrossRef]

14. Farnham, C.; Nakao, M.; Nishioka, M.; Nabeshima, M.; Mizuno, T. Study of mist-cooling for semi-enclosed spaces in Osaka, Japan. Procedia Environ. Sci. 2011, 4, 228-238. [CrossRef]

15. Zhu, L.; Xue, X.; Jia, W.; Ding, S.; Sun, Z. Application of CFD technology in air-assisted spraying in orchard and analysis of its prospects. J. Drain. Irrig. Mach. Eng. 2014, 32, 776-782.

16. Brandl, D.; Mach, T.; Heimrath, R.; Edtmayer, H.; Hochenauer, C. Thermal evaluation of a component heating system for a monastery cell with measurements and CFD simulations. J. Build. Eng. 2021, 39, 102264. [CrossRef]

17. de Almeida Leão, R.X.; Silva Amorim, L.; Ferreira Martins, M.; Belich Junior, H.; Sarcinelli, E.; Amarante Mesquita, A.L. Airborne flow dynamics near free-falling bulk materials: CFD analysis from analytical pressure field. Powder Technol. 2021, $385,1-11$. [CrossRef]

18. Negi, P.; Subhash, M. Method to control flow separation over wind turbine blade: A CFD study. Mater. Today Proc. 2021. [CrossRef]

19. Sureshkumar, R.; Kale, S.R.; Dhar, P.L. Heat and mass transfer processes between a water spray and ambient air-II. Simulations. Appl. Therm. Eng. 2008, 28, 361-371. [CrossRef]

20. Sureshkumar, R.; Kale, S.R.; Dhar, P.L. Heat and mass transfer processes between a water spray and ambient air-I. Experimental data. Appl. Therm. Eng. 2008, 28, 349-360. [CrossRef]

21. Zhang, W.; Yuan, J.; Zhou, B.; Li, H.; Yuan, Y. The influence of axial-flow fan trailing edge structure on internal flow. Adv. Mech. Eng. 2018, 10(11), 168781401881174. [CrossRef]

22. Söylemez, E.; Alpman, E.; Onat, A.; Hartomacıŏlu, S. CFD analysis for predicting cooling time of a domestic refrigerator with thermoelectric cooling system. Int. J. Refrig. 2021, 123, 138-149. [CrossRef]

23. Zhang, X.; Weerasuriya, A.U.; Tse, K.T. CFD simulation of natural ventilation of a generic building in various incident wind directions: Comparison of turbulence modelling, evaluation methods, and ventilation mechanisms. Energy Build. 2020, 229 , 110516. [CrossRef]

24. Khan, S.A.; Ibrahim, O.M.; Aabid, A. CFD analysis of compressible flows in a convergent-divergent nozzle. Mater. Today Proc. 2021. [CrossRef]

25. Xie, B.; Xiao, F. Toward efficient and accurate interface capturing on arbitrary hybrid unstructured grids: The THINC method with quadratic surface representation and Gaussian quadrature. J. Comput. Phys. 2017, 349, 415-440. [CrossRef]

26. Gullberg, P.; Löfdahl, L. Fan modelling in CFD using RANS with MRF, limitations and consistency, a comparison between fans of different design. In Vehicle Thermal Management Systems Conference and Exhibition (VTMS10); Woodhead Publishing: Cambridge, UK, 2011; pp. 423-433.

27. Boulard, T.; Roy, J.C.; Lamrani, M.A.; Haxaire, R. Characterising and Modelling the Air Flow and Temperature Profiles in a Closed Greenhouse in Diurnal Conditions. IFAC Proc. Vol. 1997, 30, 37-42. [CrossRef]

28. Liu, W.; Wang, J.B.; Liu, Z.C. A method of fluid dynamic analysis based on Navier-Stokes equation and conservation equation on fluid mechanical energy. Int. J. Heat Mass Transf. 2017, 109, 393-396. [CrossRef]

29. Zhang, Y.C.; Yi, D.L.; Feng, D.Y. Fan Design and Selection; Chemical Industry Press: Beijing, China, 2011.

30. Ye, W.; Wang, X.; Liu, Y.; Chen, J. Analysis and prediction of the performance of free- piston Stirling engine using response surface methodology and artificial neural network. Appl. Therm. Eng. 2021, 188, 116557. [CrossRef]

31. Breig, S.J.M.; Luti, K.J.K. Response surface methodology: A review on its applications and challenges in microbial cultures. Mater. Today Proc. 2021. [CrossRef]

32. Zhao, W.; Ma, A.; Ji, J.; Chen, X.; Yao, T. Multi-Objective Optimization of a Double-Side Linear Vernier PM Motor Using Response Surface Method and Differential Evolution. IEEE Trans. Ind. Electron. 2019, 99. [CrossRef]

33. Murugan, P.C.; Joseph Sekhar, S. Species - Transport CFD model for the gasification of rice husk (Oryza Sativa) using downdraft gasifier. Comput. Electron. Agric. 2017, 139, 33-40. [CrossRef]

34. Bing, X.; Sun, D.; Song, S.; Xue, X.; Dai, Q. Simulation and experimental research on droplet flow characteristics and deposition in airflow field. Int. J. Agric. Biol. Eng. 2020, 13, 16-24.

35. Mahgoub, A.O.; Ghani, S. Numerical and experimental investigation of utilizing the porous media model for windbreaks CFD simulation. Sustain. Cities Soc. 2021, 65, 102648. [CrossRef]

36. Saneinejad, S.; Moonen, P.; Defraeye, T.; Derome, D.; Carmeliet, J. Coupled CFD, radiation and porous media transport model for evaluating evaporative cooling in an urban environment. J. Wind Eng. Ind. Aerodyn. 2012, 104-106, 455-463. [CrossRef]

37. Houcine, A.; Maatallah, T.; Alimi, S.E.; Nasrallah, S.B. Optical modeling and investigation of sun tracking parabolic trough solar collector basing on Ray Tracing 3Dimensions-4Rays. Sustain. Cities Soc. 2017, 35, 786-798. [CrossRef]

38. Zhao, B.J.; Hou, D.H.; Chen, H.L.; Yu, W.; Qiu, J. Optimization design of a double-channel pump by means of orthogonal test, CFD, and experimental analysis. Adv. Mech. Eng. 2014, 6, 1-10. [CrossRef] 